\title{
Papilloma of the Umbilicus
}

\author{
R. Vijayabhaskar • O. L. Sadasivam • \\ K. S. Kirushnakumar
}

Received: 28 March 2012 / Accepted: 10 September 2012 /Published online: 18 September 2012

(C) Association of Surgeons of India 2012

\begin{abstract}
We present an interesting and rare case of umbilical papilloma associated with Carcinoma cervix
\end{abstract}

Keywords Umbilical wart · Papilloma $\cdot$ HPV

A 47-year-old female presented with history of dysmenorrhea. Examination revealed ulcer in cervix; biopsy from it showed carcinoma in situ changes with foci of invasive carcinoma. She underwent Wertheim's hysterectomy, and at the time of surgery incidentally found to have a warty growth in the umbilicus (Fig. 1), which was excised. The postoperative period was uneventful. The final histopathology report showed features suggestive of microinvasive squamous cell carcinoma of cervix with negative nodes. Sections from umbilical growth showed features of benign squamous papilloma (Fig. 2).

\section{Review of Literature}

Warts are benign tumors that commonly involve skin and other epithelial tissues. The etiologic agents for these lesions are a class of double-stranded DNA viruses called human papilloma viruses (HPV). HPV infects individuals of all ages. Infection occurs as a result of person-to-person spread, including sexual transmission, vertical transmission and exposure to virus in the environment $[1,2]$.

R. Vijayabhaskar $(\bowtie) \cdot$ O. L. Sadasivam

Department of Surgical oncology,

Meenakshi Mission Hospital and Research Centre,

Lake area, Melur road,

Madurai 625 107, India

e-mail: drvijayabhaskar@gmail.com

\section{K. S. Kirushnakumar}

Department of Radiation oncology,

Meenakshi Mission Hospital and Research Centre,

Madurai, India
Common warts represent approximately $70 \%$ of all warts. These warts initially present as a smooth flesh colored papule, which later evolves into dark brown hyperkeratotic nodule. Common warts are located preferentially in hands, but can occur in any part of the body [1].

The diagnosis is usually made by clinical examination. Koilocytosis, if identified by biopsy, is pathognomonic. Treatment aims at increasing the clinical disease free interval and decreasing the bulk of disease, thereby enabling the immune system to act upon the remaining virus infected cells. Topical applications of caustics, cantharidin and
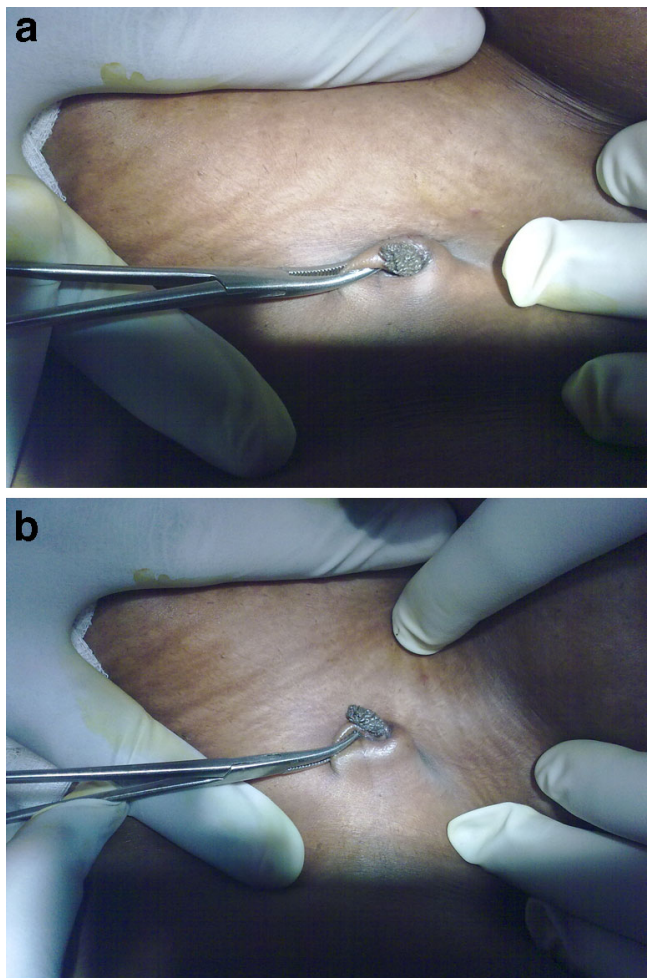

Fig. 1 a, b: Clinical photograph of papilloma in the umbilicus. Note the classic hyperkeratotic nature 

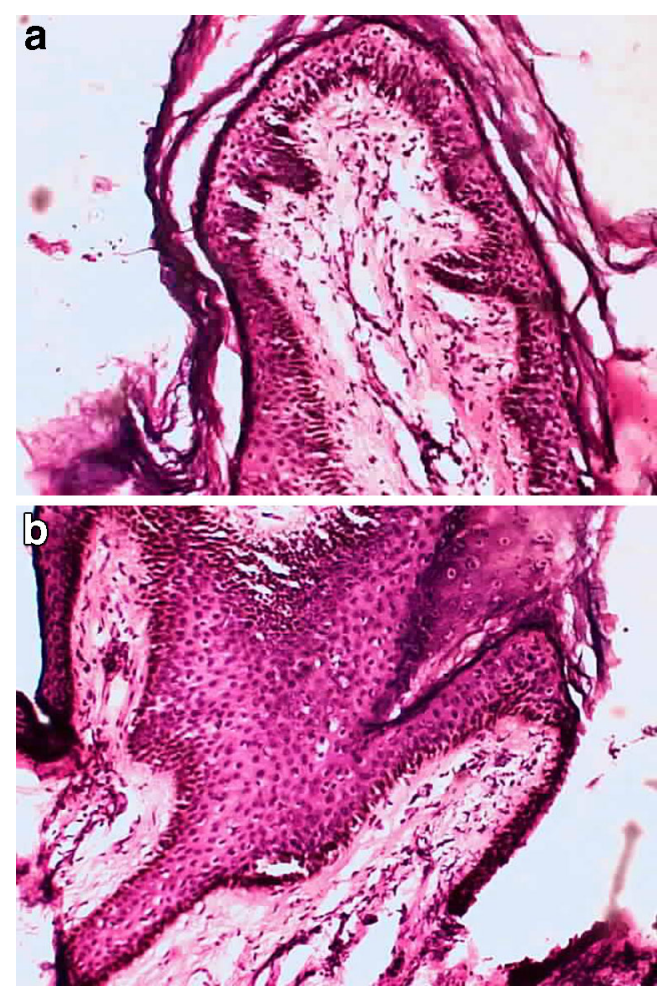

Fig. 2 a, b: Microscopic picture of umbilical papilloma. It shows fibromuscular stalk covered with squamous epithelium, showing normal maturation pattern podophyllin are effective in small lesions. Cryotherapy, electrodessication and surgical excision are other treatment options [1,2].

Human papilloma virus which commonly present as cutaneous/genital warts are also implicated as an etiology of carcinoma cervix, especially strains 16 and 18 [3]. This patient had papilloma of umbilicus, a rare presentation along with carcinoma of cervix; both are of HPV etiology. In our case, HPV etiology was not confirmed by specific tests but is presumed. So far, very few cases of umbilical papilloma have been reported in western literature $[4,5]$. and no case reports in have been reported in Indian publications.

\section{References}

1. Plasencia JM (2000) Cutaneous warts: diagnosis and treatment. Prim Care 27(2):423-34

2. Kuykendall-Ivy TD, Johnson SM (2003) Evidence-based review of management of nongenital cutaneous warts. Cutis 71(3):213-22

3. Scheinfeld N, Lehman DS (2006) An evidence-based review of medical and surgical treatments of genital warts. Dermatol Online J 12(3):5

4. Nathan M (1994) Umbilical warts: a new entity? Genitourin Med 70:49-50

5. Carson NB (1917) Papilloma of the umbilicus. Ann Surg 65 (2):199-201 